The book is lucidly written, so that any difficulties it may present would come from the ideas described and not from their expression. The early chapters which are devoted to tho discovery of quasars and their main observational properties are fairly straightforward, and should be understood by the general reader with seientific and astronomical interests for whom the book, according to tho blurb, has boen written. The theoretical chapters discussing the physical basis of eurrent interpretations are inevitably more difficult. A brief account is given of radiation procosses, tho acceleration of fast particles, magnetohydrodynamics, relativity and cosmology. This is a formidable list, but I believe that the general reader will glean from this part of tho book the type of idea which each of these subjects is called on to provide.

Separate mention should be made of the chapter entitlod "Stars", which is the most difficult but most rewarding in the book. It deals with the stability of large masses in the manner made famous by Eddington, that is, by using simple physical considerations to derive their main proporties. I would like to diroct attention especially to the extension of Eddington's method to the case when general relativistic effects are important. Chandrasekhar has found by some difficult analysis exactly how the stability criterion is altered by these effects. Here a relatively simple analysis is used to obtain a reasonable approximation to this new criterion. This section will be read with gratitude not only by the general reader but also by astronomers who are not experts in relativity. I think Eddington would have onjoyed this extension of his method, although perhaps hewould have addod whimsically that the authors give a rather low mark (10 per cent) to this relativistic instability as the possible origin of quasars.

One day we will understand the origin of quasars, and then this book will have to be rewritten. Even now, however, we can claim that we are living in the heroic age of astronomy (and it is no disrespect to the groat astronomers of the past to recognize this). The reader who masters a fair fraction of Kahn and Palmer can share in the excitement of this age, and will be prepared to understand in good part the great discoveries that are still to come.

D. W. Sciama

\section{OPTIMAL CONTROL}

\section{Optimization of Stochastic Systems}

Topics in Discrete-Time Systems. By Masanao Aoki. (A Series of Monographs and Text-books in Mathematics in Science and Engineering, Vol. 32.) Pp. xv +354. (New York: Academic Press, Inc.; London: Academic Press, Inc. (London), Ltd., 1967.) 1168.

Thrs is the thirty-second text in an excellent series of books on mathematics with practical application which is being edited by $\mathbf{R}$. Bellman. Tho present author, M. Aoki, is an eminent research worker in the field of control system optimization and fifteen of his 143 referonces are to important publications of his own.

As indicated by the word "stochastic" in the title, the problem of optimization is studied for cases in which the systom is subjoct to randomly varying inputs. Those inputs can be either additive, as with noise or random signals to be followed, or multiplicative, as when gains and time constants vary randomly. The whole study is performed using discrete-time so that systems aro always described by difference equations. Thus the development of statistical methods is more straightforward than with a continuous-timo study which may be ultimately nocessary in many cascs. Tho resulting unificd treatment, however, is a commendable feature of the book.

Muoh of the book is concerned with the derivation of what the author calls "optimal Baycsian control". This involves the manipulation by the chain and Bayes's rules of conditional probability densities which are used in recurrence relations for expected future cost. Then the process of deriving optimal control corresponds to the method of dynamic programming. The optimal control policies aro applied firstly when noise and plant parameters are known constants, then whon some of the parameters are unknown but assumed constant, and finally when such parameters are themselves stochastic.

A chapter is devoted to the problem of how to operate on noisy measurements in order to make tho best estimate of the quantities being measured. Three methods are studied: least-squares, maximum likelihood and optimal Bayesian estimation, and their inter-rolation is examined. The Kalman filter is derived as an example of the latter method.

The convergence of Bayesian optimization is considered together with Kalman's concept of controllability and observability applied to stochastic systems. The question of the stability of systems is also studied using stochastic Lyapunov functions. 'There is a long chapter concerned with approximations which may be mado to simplify the formulation and implementation of optimal control policies. More work may be needed in this direction before the methods are applied in practice. The cortainty equivalence principlo, pseudoinvorso matrices and sufficient statistics and martingales are interesting features which enter naturally into the work and are given some explanation.

The basic roquirement of the reader is a working knowledge of matrices, vector spaces and conditional probabilities. Throughout the book, the author tries to bo gentlo to the uninitiated by the use of illustrative examples given in ascending order of difficulty. Although no exercises are set for the reader, it will form a good textbook for students of advanced control theory and it will be an extremely valuable reference book for researchers and teachers of control of stochastic systems.

\section{A. P. Roberts}

\section{THIS IS TRIBOLOGY}

\section{Lubrication and Lubricants}

Edited by Eric R. Braithwaite. Pp. xiv $+568+191$ illustrations and 46 tables. (London, Amsterdam and New York: Elsevier Publishing Company Ltd., 1967.) $170 s$. Presentation of a subject which has its origin in traditional practice but wherein modern development has occurred in a number of scientific disciplines poses many problems. Not least of these is the probability that the reader may bo expert in one facet while having only a superficial knowledge of the remainder. Thus, as in this book, which deals with chemistry, metallurgy and soveral aspects of ongineoring, matter which is descriptive of present or past practice must be blended with rigorous treatment of current scientific contributions. Collaborators in this volume have overcomo these difficulties quite skilfully, presenting good reviews of current research in each field against a background of historical or other introductory mattor sufficiont to facilitate a multidisciplinary approach. Perhaps, because the planning of the volume anticipated the Jost Report, the word tribology is not used although the volumo is itsolf a good example of the multi-disciplinary approach denoted by this term.

In an introductory survey, Rowe departs from the conventional concern with the contact of asperities and introduces the subject of boundary lubrication by analogy with the lubrication by a soft solid of flat metal plates loaded in compression. 'Tho resistanco to latoral sliding is proportional to the yicld strength in shear of the soft solid, and the maximum eompressive stress which ean be withstood by the motal plates is, of course, thoir yield strength in compression. The yield strength in shear is related to yield strength in compression by a ratio of $1 / 2$, 